\title{
PSYCHIATRIC COMORBIDITIES IN PEOPLE WITH EPILEPSY
}

1Marco Mula MD, ${ }^{2}$ Andres M Kanner MD, ${ }^{3}$ Nathalie Jette MD MSc FRCPC, 4,5 Josemir

\section{W Sander FRCP}

${ }^{1}$ Institute of Medical and Biomedical Education, St George's University of London and the Atkinson Morley Regional Neuroscience Centre, St George's University Hospitals NHS Foundation Trust, London, United Kingdom

2Department of Neurology, Comprehensive Epilepsy Center and Epilepsy Division, University of Miami, Miller School of Medicine, Miami, FL, USA

3Department of Neurology, Division of Epilepsy and Division of Health Outcomes and

Knowledge Translation Research, Icahn School of Medicine at Mount Sinai, New York, NY, USA

4NIHR UCL Hospitals Biomedical Research Centre, UCL Queen Square Institute of

Neurology, Queen Square, London WC1N 3BG, \& Chalfont Centre for Epilepsy, Chalfont St Peter, SL9 0RJ, United Kingdom

${ }^{5}$ Stichting Epilepsie Instellingen Nederland - SEIN, Achterweg 5, Heemstede 2103SW,

Netherlands

Correspondence:

Dr Marco Mula MD PhD FRCP FEAN

Atkinson Morley Regional Neuroscience Centre

St George's University Hospitals NHS Foundation Trust

Blackshaw Road

London SW17 0QT

United Kingdom

Tel. +442087254322

Fax +442087254591

Email:mmula@sgul.ac.uk

Character count title (<96): 62; Word count for the abstract $(<250)$ : 150 ;

Word count for the paper ( $<5000)$ : 4385 ;

Number of references (max 60): 60; Number of tables (<8): 4

Search terms: epilepsy, antiepileptic drugs, depression, psychosis, treatment, comorbidity 


\section{ROLE OF FUNDING AND ACKNOWLEDGMENTS}

This work did not receive any specific funding.

NJ receives research grant funding from NINDS (NIH U24NS107201 and NIH

IU54NS100064) and PCORI paid to her center for work unrelated to this manuscript. JWS is based at NIHR University College London Hospitals Biomedical Research Centre, which receives a proportion of funding from the UK Department of Health's Research Centres funding scheme. He also receives research support from the Marvin Weil Epilepsy Research Fund, the UK Epilepsy Society, and the Christelijke Vereniging voor de Verpleging van Lijders aan Epilepsie, The Netherlands. MM and AMK report no additional funding.

\section{DISCLOSURE}

MM reports personal fees from UCB, Eisai, Bial, Elsevier, outside the submitted work; in addition, he also has intellectual property rights with Springer and Elsevier. AK reports personal fees from Eisai and Frontline Medical Communications, outside the submitted work. $\mathrm{NJ}$ received an annual honorarium for her work as Associate Editor of Epilepsia and is a member of the Editorial Board of Neurology. JWS reports personal fees from Eisai, UCB and Zogenix, grants from Eisai, UCB, NEF and GW Phama, outside the submitted work; he is a member of the Editorial Board of the Lancet Neurology. 


\begin{abstract}
Psychiatric disorders are relatively frequent in people with epilepsy, with a lifetime history identified in one of every three individuals. Theories of comorbidity are complex, but recurring associations between epilepsy and psychiatric conditions suggest overlap that is more than simple co-occurrence; many have noted that psychiatric disorders are an important prognostic marker of epilepsy. Focusing primarily on the last five years, we review the latest evidence concerning the nature of the association between epilepsy and psychiatric comorbidities. We address the way psychiatric comorbidities affect the long-term management of people with epilepsy and consider how to screen for and diagnose psychiatric comorbidities in routine clinical practice, considering the heterogeneity of clinical scenarios in which psychiatric symptoms can occur. We discuss issues regarding the treatment of psychiatric comorbidities in people with epilepsy, including interactions between antiepileptic drugs and psychotropic medications, common side effects of antidepressants and antipsychotics and seizure risk associated with these drugs.
\end{abstract}




\section{INTRODUCTION}

According to the new International League Against Epilepsy (ILAE) definition, epilepsy is a disorder of the brain characterised by recurrent seizures but also by its "neurobiological, cognitive, psychological and social consequences"1.

Psychiatric comorbidities in people with epilepsy are due largely to psychosocial and biological factors. Epilepsy is still a stigmatised condition, leading to discrimination and social withdrawal. In addition, significant social limitations (e.g. loss of driving license) and the unpredictability of seizures can lead to poor self-esteem and depression. From a neurobiological perspective, neuroimaging studies in people with primary psychiatric conditions such as depression or schizophrenia, have shown abnormalities in brain networks overlapping with those involved for example in temporal lobe epilepsy, particularly in the amygdala and the hippocampi ${ }^{2}$. People with epilepsy, however, can also present with psychiatric symptoms peri-ictally, either preceding, during or following a seizure, or as a consequence of the treatment, antiseizure medications or epilepsy surgery.

Psychiatric problems could be due to shared neurobiological mechanisms, a consequence of having epilepsy or simply due to the unfortunate occurrence of two conditions in the same individual. Nevertheless, the management of these people can be challenging regardless of the causes. For this reason, physicians must identify comorbid psychiatric disorders and incorporate them into the comprehensive individual management. Accordingly, a multidisciplinary approach is required. This entails the need for health care professionals in other disciplines such as psychiatrists, clinical psychologists, neuropsychologists psychiatric nurses, and social workers, to ensure the individual receive the best management. 
We review current evidence about the nature of the association between epilepsy and psychiatric comorbidities and the role of psychiatric comorbidities in the long-term management of people with epilepsy. We assess the evidence on screening and diagnosing in routine clinical practice considering the heterogeneity of clinical scenarios where psychiatric symptoms occur. We also discuss issues regarding the treatment of psychiatric comorbidities in people with epilepsy, including interactions between antiseizure and psychotropic medications and their relevant side effects. Lastly, we review the evidence on whether antidepressants and antipsychotics are associated with seizure risk.

\section{SEARCH STRATEGY AND SELECTION CRITERIA}

Articles published between 1 ${ }^{\text {st }}$ Dec 2013 and 31 July 2019 were identified through searches in PubMed and Embase using the search terms "comorbidity", "comorbid*", "psychiatric disorders", “depression”, “anxiety”, "psychosis", “seizure, epilepsy and convulsion”, “epile*", "seizure*" and "convuls*". No language restrictions were applied. This search generated 638 abstracts which were reviewed by an author (MM). Articles were selected based on originality and relevance to the present topic. Additional articles were identified from the authors' own files and from chosen bibliographies.

\section{EPIDEMIOLOGY}

Data from cross-sectional studies show that all psychiatric disorders seem to occur in a higher proportion of adults and children with epilepsy than in those without epilepsy.

In adults, a meta-analysis of 14 population-based studies including over 1,000,000 participants showed an overall prevalence of active (current or last 12 months) depression in 
epilepsy of $23.1 \%(95 \% \mathrm{CI} 20.6 \%-28.3 \%$; I2=97.7\%) with increased overall risk of 2.7 $\left(95 \% \mathrm{CI} 2.09-3.6 ; \mathrm{I}^{2}=85.1 \%\right)$ compared with the general population ${ }^{3}$. These estimates, however, varied considerably across studies depending on the ascertainment source (i.e. selfreport vs. screening tools vs. structured clinical interviews), countries, regions and settings. A meta-analysis of 27 reports of anxiety disorders in over 3,000 people with epilepsy showed a pooled prevalence of $20.2 \%\left(95 \%\right.$ CI $\left.15.3-26.0 ; \mathrm{I}^{2}=92.1\right)$ with generalised anxiety disorder being most common $(10.2 \%$; 95\%CI 7.7\%-13.5\%) . Another meta-analysis of 57 studies of psychosis and related disorders, including more than 40,000 subjects, showed a pooled prevalence of $5.6 \%(95 \% \mathrm{CI} 4.8 \%-6.4 \%$; I2> $70 \%)$ in unselected individuals increasing to $7 \%$ (95\%CI 4.9\% - 9.1\%; I $2>70 \%)$ in people with mesial temporal lobe epilepsy (TLE), with a pooled odds ratio for risk of psychosis compared to the general population of $7.8(95 \% \mathrm{CI}$ $\left.2.8-21.8 ; \mathrm{I}^{2}>70 \%\right)^{5}$. The pooled prevalence of psychogenic non-epileptic seizures (PNES) in people with epilepsy in a meta-analysis was $12 \%\left(95 \%\right.$ CI $\left.10 \%-14 \% ; I^{2}=92.7 \%\right)$ while the prevalence of epilepsy in those with PNES was 22\% (95\%CI 20\%-25\%; I $2=95.5 \%)^{6}$.

Data from children with epilepsy are not different despite an obvious emphasis on developmental disorders. A population-based study in 85 children and adolescents (aged 5-15) with active epilepsy in England reported a prevalence of attention deficit hyperactivity disorder (ADHD) of around 33\%, autism spectrum disorder (ASD) of $21 \%$, depression of $7 \%$ and anxiety of $13 \% \%^{7}$. A nationwide Norwegian registry study in an unselected paediatric population of over 1,000,000 children reported developmental and psychiatric comorbidities in $43 \%$ of children with epilepsy, with overall odds ratios (compared with the general child population) of $10.7(95 \% \mathrm{CI} 9.5$ - 12.1) for autism, $5.4(95 \% \mathrm{CI} 4.8-5.9)$ for $\mathrm{ADHD}, 2.3$ $(95 \%$ CI $1.8-3.0)$ for anxiety disorders and $1.8(95 \%$ CI $1.4-2.5)$ for depression ${ }^{8}$. The use of 
the International Classification of Diseases (ICD) codes to identify psychiatric disorders in many of these studies introduces an important limitation as ICD codes have low sensitivity for psychiatric conditions, leading to possible underestimation of their occurrence 9 .

Cross-sectional epidemiological studies provide estimates of the size of the problem but do not help to clarify the nature of the association. Data from prospective observational studies clearly indicate that the relationship between epilepsy and psychiatric disorders is bidirectional. This notion was established over ten years ago and the majority of studies on this subject were published before 2013. More recent studies have further confirmed this observation. A large UK observational cohort study involving over 10,000,000 subjects found that depression was associated with a 2.5 -fold $(95 \%$ CI $2.49-2.60)$ increased risk of developing epilepsy ${ }^{10}$. Suicide risk was increased 2.9 fold (95\%CI 2.5-3.4) even before the diagnosis of epilepsy ${ }^{11}$. All these findings suggest the presence of shared pathogenic mechanisms between epilepsy and all major psychiatric disorders. It is also tempting to speculate that psychiatric disorders, in some cases, may represent the premorbid phase of some epileptic syndromes. This specific scenario may have major implications in terms of future treatments and the development of disease modifying agents.

\section{IMPLICATIONS FOR CLINICAL PRACTICE}

In epilepsy, treatment and prognosis are dependent on the accurate definition of the epilepsy syndrome. It would then be reasonable to apply the same model for psychiatric comorbidities (for example psychiatric disorders being more common in temporal lobe epilepsy as compared to generalised syndromes). The relative contribution of syndrome-specific variables is still unclear and clinical evidence suggests that psychiatric comorbidities do not 
necessarily respect such borders. It is now evident that psychiatric comorbidities have to be considered when informing people about the prospects of long-term prognosis of the epilepsy itself.

Psychiatric comorbidities have been historically associated with poor quality of life in adults $^{12}$ and children ${ }^{13}$ with epilepsy but there are now data suggesting their role as a prognostic indicator. A population-based cohort study involving $10,595,709$ people from the UK showed that depression is associated with high comorbidity rates, as measured by the Charlson Comorbidity Index, and that the severity of the depression itself (based on the type of treatment received) correlates with a lower odds of achieving seizure remission in a Canadian cohort ${ }^{10}$. Psychiatric comorbidities are associated with a high risk of side effects, especially cognitive complaints and psychiatric side effects ${ }^{14}$. Psychiatric comorbidities are associated with a four-fold increased risk of drug resistance in focal15 and generalised epilepsies ${ }^{16}$. This is further confirmed by a large cohort study from Italy in 1006 people with newly diagnosed epilepsy followed for a median of 16 years, showing that the absence of psychiatric comorbidities predicts early and long-term seizure freedom ${ }^{17}$.

The impact of psychiatric comorbidities in terms of seizure-outcome and psychiatricoutcome, in epilepsy surgery, is complex and yet to be established. Some studies have found a lower probability of achieving seizure-freedom after temporal lobectomy ${ }^{18}$, while others have refuted these findings ${ }^{19}$. The same holds true for psychiatric outcomes, as some studies showed an increased risk of recurrence of depression or anxiety during the first year after surgery ${ }^{20}$ while other studies showed long term improvement ${ }^{21}$. Psychiatric comorbidities are associated with premature mortality in epilepsy ${ }^{22}$. This may be due to a variety of reasons, including increased risk of substance or alcohol abuse ${ }^{23}$, increased risk of injury ${ }^{24}$ and increased suicide rates ${ }^{11}$. Data from a population-based study of over 
57,000 people in Sweden showed that females with epilepsy and psychiatric comorbidities had a 5-fold increased risk of sudden unexpected death in epilepsy (SUDEP) compared with those without such comorbidities ${ }^{25}$.

Lastly, it is evident that psychiatric comorbidities increase the global burden of epilepsy from a public health perspective with increased health costs ${ }^{26}$. People with epilepsy and psychiatric disorders have high health resource utilization, including increased emergency department admissions and outpatient visits ${ }^{27}$. Data from a US nationwide study assessing almost 400,000 hospital admissions showed that psychiatric comorbidities, depression and psychosis in particular, increase length-of-stay and inpatient costs for people with epilepsy ${ }^{28}$.

\section{SCREENING FOR PSYCHIATRIC COMORBIDITIES}

Despite robust evidence about the frequency and clinical implications of psychiatric disorders in epilepsy, these problems are still underdiagnosed and undertreated. A recent survey reported that around $50 \%$ of epilepsy specialists routinely screen for psychiatric disorders 29 . Barriers to diagnosis and management of psychiatric comorbidities are complex and multifactorial. These include, amongst other factors, cultural barriers to mental health issues, lack of training of neurologists and psychiatrists about these comorbidities and lack of allocated resources for a multidisciplinary approach ${ }^{30}$ (Table $\left.\mathbf{1}\right)$.

In the general population, a few screening tools are available in primary and secondary care settings for almost all major psychiatric conditions. These tools have been shown to be costeffective because they are short, standardised against DSM criteria and less resourceintensive than a full clinical interview. In the past, the validity of these instruments in people with epilepsy was a major barrier to their use in routine clinical practice. As described in this 
section, there are now good data on the validity of clinical instruments for depression and anxiety in adults and for ADHD in children.

A systematic review of studies validating 16 screening tools for depression in adults with epilepsy showed that the Neurological Disorders Depression Inventory for Epilepsy (NDDIE), validated in 13 languages, is the most efficient and practical screening instrument for a major depressive episode in a variety of settings ${ }^{31}$. The NDDI-E has also been validated for suicidality with good sensitivity and specificity 32 and this should allow the development of well-defined clinical pathways for suicide prevention.

Other well-known, self-rating scales, such as the Beck Depression Inventory II (BDI-II) and the Patient Health Questionnaire 9 (PHQ-9) have also been shown to be valid in epilepsy but require use of cut-off scores higher than those adopted in the general population (general population BDI-II = 10, PHQ-9 = 5; epilepsy BDI-II = 15, PHQ-9 = 10) $)^{31}$. This can be partially explained by the heterogeneity of clinical presentations of depression in epilepsy, but also highlights the need to adapt these questionnaires to the specific needs of people with epilepsy in order to maximize their sensitivity and specificity.

The Hamilton Depression Rating Scale (HDRS) has been used as an outcome measure in clinical trials of depression outside epilepsy and it has also been validated in epilepsy ${ }^{33}$. This will allow the development of outcome studies of depression in people epilepsy whose results will be comparable with those from the general population.

Two main clinical instruments have been validated for symptoms of anxiety in adults with epilepsy; the Hospital Anxiety and Depression Scale (HADS) and the Generalised Anxiety Disorder 7 (GAD-7). While studies on the validity of the HADS in epilepsy provide conflicting results ${ }^{34}$, the validity and cost-effectiveness of the GAD-7 seem to be well 
established ${ }^{35}$. Discrepancies among studies are due to the fluctuating nature of anxiety symptoms and the nonconforming phenomenology of psychiatric symptoms in epilepsy.

Data on screening instruments in children with epilepsy are still limited. A systematic review on the management of ADHD in epilepsy reported good evidence for the use of the Strength and Difficulties Questionnaire (SDQ) ${ }^{36}$. Data on clinical instruments for depression and anxiety in the paediatric population are scant but this is due to current clinical practice in general. In fact, two comprehensive documents from the American Academy of Child and Adolescent Psychiatry recommend the use of DSM or ICD-based symptom checklists in the general population 37,38 . A 12-item, self-report screening tool for depression in people with epilepsy aged 12-17 years, called NDDI-E-Youth, has been developed ${ }^{39}$ but further studies in this area are needed.

\section{DIAGNOSTIC ISSUES}

After a positive screen it is important to confirm the diagnosis, as psychiatric symptoms can be seen in a variety of clinical scenarios including peri-ictal symptoms, side effects of drugs or comorbid psychiatric disorders. The boundaries between these scenarios are often blurred and, as already discussed, people with a psychiatric comorbidity are also more likely to present with psychiatric side effects from antiseizure medications.

Historically, psychiatric symptoms in epilepsy have been categorised according to their temporal relationship with seizures and the practicality of this is well-known as they define different clinical scenarios which are summarised in Table 2.

The prevalence and pathophysiology of peri-ictal symptoms are largely unknown and data come from adult samples. Postictal psychoses are probably the most frequently described and 
investigated symptom pattern and a meta-analysis reported a point prevalence of $2 \%(95 \% \mathrm{CI}$ $1.2 \%-2.8 \%)^{5}$. Postictal psychoses are typically seen in people with temporal lobe epilepsy and they are characterised by higher rates of violent behaviours and suicide attempts than interictal psychoses ${ }^{40}$. Conversely, non-psychotic postictal psychiatric symptoms are often not recognised, in large part because they are short-lasting and clinicians fail to investigate their presence. In a systematic study of people with drug-resistant focal epilepsy, $43 \%$ had postictal symptoms of depression, $45 \%$ postictal anxiety and $7 \%$ psychotic symptoms. These occurred in more than half of their seizures and lasted for a median of 24 hours ${ }^{41}$.

Psychiatric symptoms as side effects of antiseizure medications are frequently reported. A retrospective analysis of medical notes of a large unselected sample from the US including 4085 adults recently started on an antiseizure medications showed that 1 in 6 individuals with epilepsy develops drug-related psychiatric side effects ${ }^{42}$. Sodium channel blockers seem to be less frequently associated with psychiatric side effects ${ }^{42}$, but there are no robust headto-head trials providing strong evidence for that. For this reason, clinicians should bear in mind that psychiatric side effects can happen with any drug in predisposed individuals, such as those with psychiatric comorbidities. Psychiatric side effects of antiseizure medications reported with a prevalence higher than $1 \%$ are summarised in Table 3.

Lastly, the clinical presentation of psychiatric comorbidities has itself been a matter of debate 43. In fact, people with epilepsy can develop psychiatric disorders clinically identical to those of individuals without epilepsy but it is also established that some develop psychiatric syndromes characterised by unusual features non adequately captured by classificatory systems such as DSM and ICD44 (Table 2). Psychiatric presentations can be atypical and sometimes challenging in people with intellectual disabilities ${ }^{45}$, where also the pattern of psychiatric side effects of antiseizure medications can be different (Table 3). 


\section{TREATMENT ISSUES}

Full remission should always be the ultimate goal of the treatment of any psychiatric comorbidity in epilepsy. As discussed in this section, current evidence on the management of psychiatric comorbidities in epilepsy is limited. There is, however, no reason to consider that guidelines of treatment for psychiatric disorders may not be valid in epilepsy. It seems reasonable, therefore, to follow standard practice bearing in mind the individualities of people with epilepsy, especially drug-interactions and risk of seizures (Table 4).

\section{Psychological interventions}

In the general population, psychological interventions are the first line treatment for all anxiety disorders and for mild to moderate depression. It is reasonable to apply this guidance also to people with epilepsy but the evidence is still limited and mainly based on quality of life data ${ }^{46}$. A recent ILAE report supported psychological interventions in people with epilepsy and mild to moderate depressive symptoms, although again the evidence level is moderate ${ }^{47}$.

Psychoeducation and psychological interventions still represent first line treatments for PNES ${ }^{48}$. No studies have specifically addressed the management of PNES in people with epilepsy, but it is obvious that explaining the diagnosis and educating individuals and caregivers about the differences between epilepsy and PNES are extremely important.

\section{Pharmacological treatments}

In the general population, antidepressants are used in moderate to severe depression and in all anxiety disorders in combination with psychological interventions. A Cochrane Review on 
antidepressants in epilepsy has, however, shown a low level of evidence due to the poor quality of studies ${ }^{49}$. There are only two placebo-controlled trials and several open studies of antidepressants including sertraline, citalopram, fluoxetine, reboxetine and mirtazapine ${ }^{50}$. These studies clearly suggest that selective serotonin reuptake inhibitors (SSRIs) and newer antidepressants are safe and effective in epilepsy but they are limited by the relatively small size and the inclusion of people with different epilepsy types (from newly diagnosed to those with drug-resistant epilepsy). These limitations probably explain the heterogeneous response rates, ranging from $24 \%$ to $97 \% 50$. Citalopram and sertraline are usually considered first-line treatments for depression in the context of a chronic health condition, and given available data, this is a sound option in people with epilepsy and depression.

There seem to be no studies examining the effectiveness of drug treatments for anxiety disorders in epilepsy but SSRIs are usually considered first-line treatment when a pharmacological treatment is needed.

Regarding antipsychotics, the evidence is also scant. A Cochrane Review ${ }^{51}$ quotes only a single controlled study investigating olanzapine (10 mg/day) as compared to haloperidol (12 $\mathrm{mg} /$ day) in 16 people with epilepsy and psychosis. This was, however, a conference abstract published 15 years ago and the study was never published. Risperidone, olanzapine and quetiapine are usually considered first line treatments in first episode psychosis. Post-ictal psychoses represent an epilepsy-specific problem and for this reason evidence is less compelling and it is not possible to apply evidence from elsewhere. Historically, a combination of benzodiazepines (i.e. clobazam) and atypical antipsychotics is often used 52 There are no studies on the use of antipsychotics in people with challenging behaviour, autism and epilepsy. Trials in persons with intellectual disabilities and challenging behaviour 
or autism without epilepsy seem to favour risperidone ${ }^{45}$. A post-hoc analysis of a subsample of 35 people from Japan from a large, controlled trial of everolimus suggested some potential beneficial effects on behavioural symptoms in people with autism and epilepsy due to tuberous sclerosis 53 .

The level of evidence is higher for treatment of ADHD in epilepsy than for other psychiatric comorbidities, despite the limited number of studies. A systematic review showed response rates for methylphenidate in children with ADHD and epilepsy between $65 \%$ and $83 \%$. Data on atomoxetine and amphetamines are available only at the anecdotal level.

\section{Interactions}

Old antiseizure medications such as carbamazepine, phenytoin and barbiturates induce drugmetabolizing enzymes such as the CYP and the UGT systems, while valproate is an inhibitor. Among newer drugs, oxcarbazepine is a weak inducer, topiramate is an inducer at daily doses over $200 \mathrm{mg}$ while other newer drugs are less likely to be culprits for drug-interactions ${ }^{54,55}$. Antidepressants are extensively metabolised by multiple systems and this can potentially lead to interactions ${ }^{54}$. Regarding tricyclics, dosage adjustments with inducers should be considered on an individual basis and this is due to a number of pharmacokinetic reasons including the large therapeutic window of this class of antidepressants and the concomitant increase in the free fraction due to a concomitant protein binding displacement interaction ${ }^{55}$. Inducers reduce the levels of SSRIs by around a quarter but again systematic dose adjustments in routine clinical practice are not needed ${ }^{55}$. Fluoxetine, fluvoxamine and, to a lesser extent, sertraline inhibit the CYP2C9 and this can possibly increase the levels of phenytoin and, to a 
lesser extent, valproate ${ }^{54,55}$. Inducers like carbamazepine, decrease the blood levels of bupropion by $90 \%$ making this interaction clinically relevant ${ }^{54}$.

All enzyme-inducing drugs reduce antipsychotic blood levels but this is markedly important for quetiapine; for instance, its use with carbamazepine is associated with undetectable levels of the antipsychotic drug even at a dose of $700 \mathrm{mg}^{55}$. There is no evidence that antipsychotics affect the blood levels of epilepsy medications.

Data on potential interactions of methylphenidate are limited to older compounds but there is no evidence of clinically relevant interactions.

Pharmacodynamic interactions are rarely systematically investigated but they can affect adherence and successful response to treatment. They are usually classified into positive and negative interactions. Positive interactions include synergistic or additive treatment effects such as the combination of SSRIs and pregabalin in some anxiety disorders ${ }^{56}$. Negative interactions include, for example, the amplification of potential side effects by the combination of two medications and these can be sedation, weight gain, sexual dysfunction, hyponatraemia, osteopenia and heart problems. For these reasons, neurologists need to familiarise themselves with the spectrum of side effects of psychotropic medications, in particular antidepressants ${ }^{54}$.

\section{Seizure risk}

Historically, psychotropic drugs were thought to be associated with an increased risk of seizures and this is reported in the information leaflet of many psychotropic medications, from antidepressants to antipsychotics. This, however, has never been based on any robust 
clinical evidence. Conversely, the analysis of seizure incidence in Phase II-III studies of psychotropic drugs approved by the Food and Drug Administration between 1985 and 2004 involving over 75,000 individuals showed that seizure incidence was not different from that of placebo. The only exception was for high-dose clomipramine $(>150 \mathrm{mg})$ which showed a standardised incidence ratio of $4(95 \%$ CI 2.6-6.0) 57.

Regarding psychostimulants, a Swedish study involving more than 21,000 children with seizures, showed no increased risk of seizures from ADHD medications ${ }^{58}$ and this has been also endorsed by a recent ILAE consensus report ${ }^{36}$.

Regarding antipsychotic drugs, clozapine has the highest risk of seizures when compared to placebo with a standardised incident ratio of 9.5 (95\%CI 7.2-12.2) $)^{57}$. Olanzapine and quetiapine carry also some risk but to a lesser extent, while all other antipsychotics are no different from placebo ${ }^{57}$. A large community-based Taiwanese study involving 288,397 people showed that second generation antipsychotics like risperidone and aripiprazole have an even lower risk of seizures than first generation drugs like chlorprothixene, thioridazine and haloperidol ${ }^{59}$.

The risk of seizures with clozapine is dose- and titration-dependent 60 although, in people with epilepsy, seizure aggravation has been reported even at low doses.

Nonetheless, it is still unknown whether all these data coming from the psychiatric realm can be directly transferred to people with epilepsy and psychiatric comorbidities. The few available open studies in epilepsy previously mentioned do not suggest deterioration in seizure frequency on a stable epilepsy drug regime.

Drug-related seizures are a complex problem and it is not just restricted to psychotropic medications. There is no doubt, however, that the incorrect over-estimation of the risk of 
seizures with psychotropic medications has had a deleterious impact on access to proper treatment in people with epilepsy and psychiatric comorbidities.

\section{CONCLUSIONS AND FUTURE DIRECTION}

Psychiatric disorders are a relatively frequent comorbidity in people with epilepsy and they need to be an integral part of the management. For this reason, epilepsy clinics should have a clear pathway for access to mental health care. There are now several screening instruments which can be adopted in routine clinical practice even in resource poor settings. In the absence of epilepsy-specific guidelines, internationally adopted guidelines concerning the treatment and management of primary psychiatric disorders should be adopted, taking into account the peculiarities of people with epilepsy.

Future studies need to clarify whether these disorders are mediators or moderators of seizure outcome; that is, are psychiatric disorders merely indicators of poor prognosis or can their early identification and prompt treatment have an impact on the prognosis of the epilepsy itself?

High quality outcome studies for major psychiatric comorbidities such as mood, anxiety disorders and psychoses in people with epilepsy are needed to develop evidence-based treatment strategies. 
Appendix 1. Authors contribution

\begin{tabular}{|l|l|l|l|}
\hline Name & Location & Role & Contribution \\
\hline Marco Mula & St George's University of & Author & Conceptualized the paper; \\
MD & London, United Kingdom & & $\begin{array}{l}\text { literature search and abstract } \\
\text { review; drafted the manuscript }\end{array}$ \\
\hline Andres & Miller School of Medicine, & Author & Revised the manuscript for \\
Nathalie & Icahn School of Medicine at & Author & Revised the manuscript for \\
Jette MD & Mount Sinai, New York & intellectual content \\
\hline Ley Sander & UCL Queen Square Institute of & Author & Conceptualized the paper; \\
MD & Neurology, Queen Square, & & Revised the manuscript for \\
& London, United Kingdom & & intellectual content \\
\hline
\end{tabular}




\section{REFERENCES (max 60)}

1 Fisher RS, Acevedo C, Arzimanoglou A, et al. ILAE official report: a practical clinical definition of epilepsy. Epilepsia 2014; 55: 475-82.

2 Dean DJ, Orr JM, Bernard JA, et al. Hippocampal Shape Abnormalities Predict Symptom Progression in Neuroleptic-Free Youth at Ultrahigh Risk for Psychosis. Schizophr Bull 2016; 42: 1619.

3 Fiest KM, Dykeman J, Patten SB, et al. Depression in epilepsy: a systematic review and meta-analysis. Neurology 2013; 80: 590-9.

4 Scott AJ, Sharpe L, Hunt C, Gandy M. Anxiety and depressive disorders in people with epilepsy: A meta-analysis. Epilepsia 2017; 58: 973-82.

5 Clancy MJ, Clarke MC, Connor DJ, Cannon M, Cotter DR. The prevalence of psychosis in epilepsy; a systematic review and meta-analysis. BMC Psychiatry 2014; 14: 75.

6 Kutlubaev MA, Xu Y, Hackett ML, Stone J. Dual diagnosis of epilepsy and psychogenic nonepileptic seizures: Systematic review and meta-analysis of frequency, correlates, and outcomes. Epilepsy Behav EB 2018; 89: 70-8.

7 Reilly C, Atkinson P, Das KB, et al. Neurobehavioral comorbidities in children with active epilepsy: a population-based study. Pediatrics 2014; 133: e1586-1593.

8 Aaberg KM, Bakken IJ, Lossius MI, et al. Comorbidity and Childhood Epilepsy: A Nationwide Registry Study. Pediatrics 2016; 138. DOI:10.1542/peds.2016-0921.

9 Fiest KM, Jette N, Quan H, et al. Systematic review and assessment of validated case definitions for depression in administrative data. BMC Psychiatry 2014; 14: 289.

10 Josephson CB, Lowerison M, Vallerand I, et al. Association of Depression and Treated Depression With Epilepsy and Seizure Outcomes: A Multicohort Analysis. JAMA Neurol 2017; published online Feb 27. DOI:10.1001/jamaneurol.2016.5042.

11 Hesdorffer DC, Ishihara L, Webb DJ, Mynepalli L, Galwey NW, Hauser WA. Occurrence and Recurrence of Attempted Suicide Among People With Epilepsy. JAMA Psychiatry 2016; 73: 80-6.

12 Agrawal N, Bird JS, von Oertzen TJ, Cock H, Mitchell AJ, Mula M. Depression correlates with quality of life in people with epilepsy independent of the measures used. Epilepsy Behav EB 2016; 62: 246-50.

13 Sano F, Kanemura H, Tando T, et al. Depressive symptoms contribute to quality of life in children with epilepsy. Eur J Paediatr Neurol EJPN Off J Eur Paediatr Neurol Soc 2014; 18: 774-9.

14 Stephen LJ, Wishart A, Brodie MJ. Psychiatric side effects and antiepileptic drugs: Observations from prospective audits. Epilepsy Behav EB 2017; 71: 73-8.

15 Nogueira MH, Yasuda CL, Coan AC, Kanner AM, Cendes F. Concurrent mood and anxiety disorders are associated with pharmacoresistant seizures in patients with MTLE. Epilepsia 2017; 58: $1268-76$.

16 Stevelink R, Koeleman BPC, Sander JW, Jansen FE, Braun KPJ. Refractory juvenile myoclonic epilepsy: a meta-analysis of prevalence and risk factors. Eur J Neurol 2018; published 
online Sept 17. DOI:10.1111/ene.13811.

17 Beghi E, Beretta S, Carone D, et al. Prognostic patterns and predictors in epilepsy: a multicentre study (PRO-LONG). J Neurol Neurosurg Psychiatry 2019; published online June 27. DOI:10.1136/jnnp-2019-320883.

18 Bell GS, de Tisi J, Gonzalez-Fraile JC, et al. Factors affecting seizure outcome after epilepsy surgery: an observational series. J Neurol Neurosurg Psychiatry 2017; 88: 933-40.

19 Altalib HH, Berg AT, Cong X, et al. Presurgical depression and anxiety are not associated with worse epilepsy surgery outcome five years postoperatively. Epilepsy Behav EB 2018; 83: 7-12.

20 Wrench JM, Rayner G, Wilson SJ. Profiling the evolution of depression after epilepsy surgery. Epilepsia 2011; 52: 900-8.

21 Ramos-Perdigués S, Baillés E, Mané A, et al. A prospective study contrasting the psychiatric outcome in drug-resistant epilepsy between patients who underwent surgery and a control group. Epilepsia 2016; 57: 1680-90.

22 Fazel S, Wolf A, Långström N, Newton CR, Lichtenstein P. Premature mortality in epilepsy and the role of psychiatric comorbidity: a total population study. Lancet Lond Engl 2013; 382: 164654.

23 Keezer MR, Bell GS, Neligan A, Novy J, Sander JW. Cause of death and predictors of mortality in a community-based cohort of people with epilepsy. Neurology 2016; 86: 704-12.

24 Gur-Ozmen S, Mula M, Agrawal N, Cock HR, Lozsadi D, von Oertzen TJ. The effect of depression and side effects of antiepileptic drugs on injuries in patients with epilepsy. Eur J Neurol 2017; 24: 1135-9.

25 Sveinsson O, Andersson T, Carlsson S, Tomson T. The incidence of SUDEP: A nationwide population-based cohort study. Neurology 2017; 89: 170-7.

26 Wilner AN, Sharma BK, Soucy A, Thompson A, Krueger A. Common comorbidities in women and men with epilepsy and the relationship between number of comorbidities and health plan paid costs in 2010. Epilepsy Behav EB 2014; 32: 15-20.

27 Hamilton KT, Anderson CT, Dahodwala N, et al. Utilization of care among drug resistant epilepsy patients with symptoms of anxiety and depression. Seizure 2014; 23: 196-200.

28 Patel RS, Elmaadawi A, Mansuri Z, Kaur M, Shah K, Nasr S. Psychiatric Comorbidities and Outcomes in Epilepsy Patients: An Insight from a Nationwide Inpatient Analysis in the United States. Cureus 2017; 9: e1686.

29 Mula M, Cavalheiro E, Guekht A, et al. Educational needs of epileptologists regarding psychiatric comorbidities of the epilepsies: a descriptive quantitative survey. Epileptic Disord Int Epilepsy J Videotape 2017; published online June 19. DOI:10.1684/epd.2017.0915.

30 Lopez MR, Schachter SC, Kanner AM. Psychiatric comorbidities go unrecognized in patients with epilepsy: 'You see what you know'. Epilepsy Behav EB 2019; published online April 23. DOI:10.1016/j.yebeh.2019.01.027.

31 Gill SJ, Lukmanji S, Fiest KM, Patten SB, Wiebe S, Jetté N. Depression screening tools in persons with epilepsy: A systematic review of validated tools. Epilepsia 2017; 58: 695-705. 
32 Mula M, McGonigal A, Micoulaud-Franchi J-A, May TW, Labudda K, Brandt C. Validation of rapid suicidality screening in epilepsy using the NDDIE. Epilepsia 2016; 57: 949-55.

33 Mula M, Iudice A, La Neve A, et al. Validation of the Hamilton Rating Scale for Depression in adults with epilepsy. Epilepsy Behav EB 2014; 41: 122-5.

34 Wiglusz MS, Landowski J, Cubała WJ. Validation of the Polish version of the Hospital Anxiety and Depression Scale for anxiety disorders in patients with epilepsy. Epilepsy Behav EB 2018; 84: 162-5.

35 Seo J-G, Cho YW, Lee S-J, et al. Validation of the generalized anxiety disorder-7 in people with epilepsy: a MEPSY study. Epilepsy Behav EB 2014; 35: 59-63.

36 Auvin S, Wirrell E, Donald KA, et al. Systematic review of the screening, diagnosis, and management of ADHD in children with epilepsy. Consensus paper of the Task Force on Comorbidities of the ILAE Pediatric Commission. Epilepsia 2018; 59: 1867-80.

37 Connolly SD, Bernstein GA, Work Group on Quality Issues. Practice parameter for the assessment and treatment of children and adolescents with anxiety disorders. $J$ Am Acad Child Adolesc Psychiatry 2007; 46: 267-83.

38 Birmaher B, Brent D, AACAP Work Group on Quality Issues, et al. Practice parameter for the assessment and treatment of children and adolescents with depressive disorders. $J$ Am Acad Child Adolesc Psychiatry 2007; 46: 1503-26.

39 Wagner JL, Kellermann T, Mueller M, et al. Development and validation of the NDDI-E-Y: a screening tool for depressive symptoms in pediatric epilepsy. Epilepsia 2016; 57: 1265-70.

40 Hilger E, Zimprich F, Pataraia E, et al. Psychoses in epilepsy: A comparison of postictal and interictal psychoses. Epilepsy Behav EB 2016; 60: 58-62.

41 Kanner AM, Soto A, Gross-Kanner H. Prevalence and clinical characteristics of postictal psychiatric symptoms in partial epilepsy. Neurology 2004; 62: 708-13.

42 Chen B, Choi H, Hirsch LJ, et al. Psychiatric and behavioral side effects of antiepileptic drugs in adults with epilepsy. Epilepsy Behav EB 2017; 76: 24-31.

43 Mula M. The interictal dysphoric disorder of epilepsy: Legend or reality? Epilepsy Behav EB 2016; 58: 7-10.

44 de Araújo Filho GM, Tarifa B, Santos RE, de Oliveira Dias AL, Ulliano JRL, Marques LHN. Clinical and sociodemographic variables associated with interictal dysphoric disorder and interictal personality in patients with drug-resistant temporal lobe epilepsy: A controlled study. Epilepsy Behav EB 2017; 69: 100-3.

45 Kerr M, Linehan C, Brandt C, et al. Behavioral disorder in people with an intellectual disability and epilepsy: A report of the Intellectual Disability Task Force of the Neuropsychiatric Commission of ILAE. Epilepsia Open 2016; 1: 102-11.

46 Michaelis R, Tang V, Wagner JL, et al. Cochrane systematic review and meta-analysis of the impact of psychological treatments for people with epilepsy on health-related quality of life. Epilepsia 2018; 59: 315-32.

47 Michaelis R, Tang V, Goldstein LH, et al. Psychological treatments for adults and children with epilepsy: Evidence-based recommendations by the International League Against Epilepsy 
Psychology Task Force. Epilepsia 2018; 59: 1282-302.

48 Gasparini S, Beghi E, Ferlazzo E, et al. Management of psychogenic non-epileptic seizures: a multidisciplinary approach. Eur J Neurol 2019; 26: 205-e15.

49 Maguire MJ, Weston J, Singh J, Marson AG. Antidepressants for people with epilepsy and depression. Cochrane Database Syst Rev 2014; : CD010682.

50 Mula M, Sander JW. Current and emerging drug therapies for the treatment of depression in adults with epilepsy. Expert Opin Pharmacother 2019; 20: 41-5.

51 Farooq S, Sherin A. Interventions for psychotic symptoms concomitant with epilepsy. Cochrane Database Syst Rev 2015; : CD006118.

52 de Toffol B, Trimble M, Hesdorffer DC, et al. Pharmacotherapy in patients with epilepsy and psychosis. Epilepsy Behav EB 2018; 88: 54-60.

53 Mizuguchi M, Ikeda H, Kagitani-Shimono K, et al. Everolimus for epilepsy and autism spectrum disorder in tuberous sclerosis complex: EXIST-3 substudy in Japan. Brain Dev 2019; 41: 110.

54 Italiano D, Spina E, de Leon J. Pharmacokinetic and pharmacodynamic interactions between antiepileptics and antidepressants. Expert Opin Drug Metab Toxicol 2014; 10: 1457-89.

55 Mula M. The pharmacological management of psychiatric comorbidities in patients with epilepsy. Pharmacol Res 2016; 107: 147-53.

56 Baldwin DS, Anderson IM, Nutt DJ, et al. Evidence-based pharmacological treatment of anxiety disorders, post-traumatic stress disorder and obsessive-compulsive disorder: a revision of the 2005 guidelines from the British Association for Psychopharmacology. J Psychopharmacol Oxf Engl 2014; 28: 403-39.

57 Alper K, Schwartz KA, Kolts RL, Khan A. Seizure incidence in psychopharmacological clinical trials: an analysis of Food and Drug Administration (FDA) summary basis of approval reports. Biol Psychiatry 2007; 62: 345-54.

58 Brikell I, Chen Q, Kuja-Halkola R, et al. Medication treatment for attention-deficit/ hyperactivity disorder and the risk of acute seizures in individuals with epilepsy. Epilepsia 2019; 60: 284-93.

59 Wu C-S, Wang S-C, Yeh I-J, Liu S-K. Comparative risk of seizure with use of first- and second-generation antipsychotics in patients with schizophrenia and mood disorders. J Clin Psychiatry 2016; 77: e573-579.

60 Williams AM, Park SH. Seizure associated with clozapine: incidence, etiology, and management. CNS Drugs 2015; 29: 101-11. 
Table 1. Barriers to access to mental health care in people with epilepsy [44].

\begin{tabular}{|c|c|c|}
\hline \multicolumn{2}{|c|}{ HEALTH-CARE PROVIDER RELATED } & POTENTIAL SOLUTIONS \\
\hline $\begin{array}{l}\text { Neurologist } \\
\text { related }\end{array}$ & $\begin{array}{l}\text { Lack of training about the psychiatric } \\
\text { aspects of neurological disorders } \\
\text { Lack of knowledge about the management } \\
\text { of psychiatric disorders and the use of } \\
\text { psychotropic drugs } \\
\text { Lack of time in the outpatient setting } \\
\text { Misconceptions about seizure risk with } \\
\text { psychotropic medications } \\
\text { Failure to educate people with epilepsy } \\
\text { and their family members about } \\
\text { psychiatric comorbidities } \\
\text { Lack of communication with psychiatrists }\end{array}$ & $\begin{array}{l}\text { Neurology and psychiatry residency } \\
\text { programs with expanded curricula covering } \\
\text { psychiatric aspects of neurological } \\
\text { disorders and vice versa } \\
\text { To implement routine use of screening } \\
\text { instruments in clinical practice } \\
\text { Well-defined clinical pathway to access } \\
\text { mental health care for people with epilepsy } \\
\text { Tertiary Epilepsy Centres should have a } \\
\text { psychiatrist as part of the team } \\
\text { Information leaflets about psychiatric } \\
\text { disorders available for individuals and to be } \\
\text { given in clinic routinely }\end{array}$ \\
\hline $\begin{array}{l}\text { Psychiatrist } \\
\text { related }\end{array}$ & $\begin{array}{l}\text { Lack of training about the psychiatric } \\
\text { aspects of neurological disorders } \\
\text { Failure to recognise all the aspects of the } \\
\text { clinical manifestations of psychiatric } \\
\text { comorbidities in epilepsy } \\
\text { Misconception about the association } \\
\text { between psychiatric comorbidities and the } \\
\text { underlying epilepsy leading to refusal to } \\
\text { treat people with epilepsy } \\
\text { Misconceptions about seizure risk with } \\
\text { psychotropic medications } \\
\text { Lack of communication with neurologists }\end{array}$ & $\begin{array}{l}\text { Neurology and psychiatry residency } \\
\text { programs with expanded curricula covering } \\
\text { psychiatric aspects of neurological } \\
\text { disorders and vice versa } \\
\text { Well-defined clinical pathway to access } \\
\text { mental health care for people with epilepsy } \\
\text { Tertiary Epilepsy Centre should have a } \\
\text { psychiatrist as part of the team }\end{array}$ \\
\hline & Y RELATED & \\
\hline
\end{tabular}




\begin{tabular}{|c|c|c|}
\hline Cultural barriers & $\begin{array}{l}\text { Individual and family members' refusal to } \\
\text { accept the existence of psychiatric } \\
\text { comorbidities } \\
\text { Stigma towards mental health problems } \\
\text { (Double-stigma) }\end{array}$ & $\begin{array}{l}\text { Information leaflets about psychiatric } \\
\text { disorders available for people and to be } \\
\text { given in clinic routinely } \\
\text { To routinely discuss about psychiatric } \\
\text { problems during the clinical consultation }\end{array}$ \\
\hline $\begin{array}{l}\text { Barriers in the } \\
\text { individual with } \\
\text { epilepsy }\end{array}$ & $\begin{array}{l}\text { Misconception that it is "normal" to feel } \\
\text { anxious and /or depressed if you have } \\
\text { epilepsy } \\
\text { Misconceptions about the chronic nature } \\
\text { of epilepsy } \\
\text { Refusal to take "more" medications }\end{array}$ & $\begin{array}{l}\text { Information leaflets about psychiatric } \\
\text { disorders available for people and to be } \\
\text { given in clinic routinely } \\
\text { To routinely discuss about psychiatric } \\
\text { problems during the clinical consultation }\end{array}$ \\
\hline \multicolumn{3}{|c|}{ ECONOMIC BARRIERS } \\
\hline Lack of resources & $\begin{array}{l}\text { Limited and/or no allocated resources to } \\
\text { mental health care. }\end{array}$ & $\begin{array}{l}\text { To implement routine use of screening } \\
\text { instruments in clinical practice } \\
\text { Well-defined clinical pathway to access } \\
\text { mental health care depending on resources }\end{array}$ \\
\hline
\end{tabular}


Table 2. Classification of psychiatric symptoms according to their temporal relation with seizures [61-66].

\begin{tabular}{|c|c|c|}
\hline \multirow[t]{3}{*}{$\begin{array}{l}\text { PERI- } \\
\text { ICTAL }\end{array}$} & PRE-ICTAL & $\begin{array}{l}\text { Symptoms preceding a seizure, mostly bilateral tonic-clonic } \\
\text { seizures; prevalence unknown; mostly described in the context of } \\
\text { temporal lobe epilepsy and include irritability, insomnia, } \\
\text { dysphoria; duration from a few hours to } 2 \text { days }\end{array}$ \\
\hline & ICTAL & $\begin{array}{l}\text { These symptoms are the main manifestations of a seizure and may } \\
\text { present as: 1) Focal aware seizures, non-motor, emotional (e.g. } \\
\text { ictal fear, ictal depression); 2) Non-convulsive status epilepticus } \\
\text { (e.g. ictal psychosis) }\end{array}$ \\
\hline & POST-ICTAL & $\begin{array}{l}\text { Symptoms following a seizure, mostly bilateral tonic-clonic } \\
\text { seizures; } \\
\text { Post-ictal psychoses: prevalence around } 2 \% \text {; florid brief-psychotic } \\
\text { episodes lasting from hours to weeks; subtle onset after } 48 \text { hours } \\
\text { of lucid interval from the seizure; high mortality risk due to high } \\
\text { suicidal ideation and violent behaviour } \\
\text { Post-ictal mood and anxiety symptoms: prevalence unknown } \\
\text { (case series suggest up to } 40 \% \text { in people with drug-resistant } \\
\text { temporal lobe epilepsy); duration a few hours up to } 1 \text { day; often } \\
\text { described as post-ictal worsening of comorbid mood and anxiety } \\
\text { disorder }\end{array}$ \\
\hline \multirow[t]{2}{*}{$\begin{array}{l}\text { PARA- } \\
\text { ICTAL }\end{array}$} & $\begin{array}{l}\text { FORCED } \\
\text { NORMALISATION }\end{array}$ & $\begin{array}{l}\text { Behavioural disturbance of acute/subacute onset including } \\
\text { psychosis, significant mood change, anxiety with } \\
\text { depersonalisation/derealisation or psychogenic non-epileptic } \\
\text { attacks AND Reduction in the total number of spikes by over } 50 \% \\
\text { in a routine EEG compared to a previous recording performed } \\
\text { during a normal mental state }\end{array}$ \\
\hline & \begin{tabular}{|l} 
ALTERNATIVE \\
PSYCHOPATHOLOGY
\end{tabular} & $\begin{array}{l}\text { Behavioural disturbance of acute/subacute onset including } \\
\text { psychosis, significant mood change, anxiety with } \\
\text { depersonalisation/derealisation or psychogenic non-epileptic } \\
\text { attacks AND Complete cessation of seizures for at least } 1 \text { week, } \\
\text { corroborated by a relative or carer }\end{array}$ \\
\hline
\end{tabular}




\begin{tabular}{|c|c|c|}
\hline \multirow[t]{2}{*}{$\begin{array}{l}\text { INTER- } \\
\text { ICTAL }\end{array}$} & EPILEPSY-SPECIFIC & $\begin{array}{l}\text { Schizophrenia-like psychosis: chronic psychosis with preserved } \\
\text { affect and without progressive cognitive deterioration; historically } \\
\text { described in the context of active temporal lobe epilepsy } \\
\text { Interictal dysphoric disorder: chronic affective-somatoform } \\
\text { syndrome characterised by mood swings with irritability with } \\
\text { multiple somatic symptoms; historically described in temporal } \\
\text { lobe epilepsy - probably not specific to epilepsy } \\
\text { Interictal personality changes: e.g. Geschwind syndrome } \\
\text { characterised by dysthymic mood with obsessionality, increased } \\
\text { philosophical/religious interests, hyposexuality and hypergraphia; } \\
\text { historically described in the context of temporal lobe epilepsy }\end{array}$ \\
\hline & $\begin{array}{l}\text { COMORBID } \\
\text { DISORDERS }\end{array}$ & Any DSM-based diagnosis \\
\hline
\end{tabular}

Para-ictal=related to significant improvement in seizure frequency/seizure freedom or neurophysiological (EEG) parameters; EEG=electroencephalogram; DSM=Diagnostic and statistical manual of mental disorders 
Table 3. Common psychiatric side effects of antiseizure medications $[26,58,64]$.

\begin{tabular}{|c|c|}
\hline Drug & Psychiatric side effects \\
\hline Barbiturates & $\begin{array}{l}\text { Depression } \\
\text { Children and individuals with intellectual disabilities: hyperactivity, irritability, } \\
\text { aggression }\end{array}$ \\
\hline Benzodiazepines & $\begin{array}{l}\text { Children, elderly and individuals with intellectual disabilities: hyperactivity, irritability, } \\
\text { aggression }\end{array}$ \\
\hline Brivaracetam & Aggressive behaviour, depression, psychosis but better tolerated than Levetiracetam \\
\hline Carbamazepine & - \\
\hline Eslicarbazepine & - \\
\hline Ethosuximide & Psychosis \\
\hline Felbamate & Anxiety, psychosis \\
\hline Gabapentin & $\begin{array}{l}\text { Children and individuals with intellectual disabilities: hyperactivity, aggression, } \\
\text { irritability }\end{array}$ \\
\hline Lacosamide & - \\
\hline Lamotrigine & Individuals with intellectual disabilities: hyperactivity, irritability, aggression \\
\hline Levetiracetam & Irritability, aggression, anxiety, depression, psychosis \\
\hline Oxcarbazepine & - \\
\hline Phenytoin & Psychosis (particularly at high serum levels) \\
\hline Pregabalin & Depression \\
\hline Rufinamide & - \\
\hline Stiripentol & Hyperactivity, irritability, aggression \\
\hline Tiagabine & Irritability \\
\hline Topiramate & Depression, psychosis, irritability \\
\hline Valproate & - \\
\hline Vigabatrin & $\begin{array}{l}\text { Psychosis, depression } \\
\text { Children and individuals with intellectual disabilities: hyperactivity, aggression, agitation }\end{array}$ \\
\hline Zonisamide & Psychosis, depression, irritability \\
\hline
\end{tabular}

Table 4. Recommendations for the management of psychiatric comorbidities in epilepsy.

\begin{tabular}{|l|l|l|}
\hline & Management & Comments \\
\hline
\end{tabular}




\begin{tabular}{|c|c|c|c|}
\hline $\begin{array}{l}\text { Peri-ictal } \\
\text { symptoms }\end{array}$ & $\checkmark$ & $\begin{array}{l}\text { Improve seizure control } \\
\text { Consider surgery as for any case } \\
\text { Treat psychiatric comorbidity if } \\
\text { present }\end{array}$ & $\begin{array}{l}\checkmark \quad \text { Psychiatric opinion in multidisciplinary } \\
\text { approach to clarify diagnosis and } \\
\text { management plan }\end{array}$ \\
\hline $\begin{array}{l}\text { Para-ictal } \\
\text { symptoms }\end{array}$ & $\checkmark$ & $\begin{array}{l}\text { Consider reducing the dose of } \\
\text { antiepileptic drug or eventually to } \\
\text { switch to alternative medication }\end{array}$ & $\begin{array}{l}\checkmark \text { Psychiatric opinion in multidisciplinary } \\
\text { approach to clarify diagnosis and } \\
\text { management plan }\end{array}$ \\
\hline Major depression & $\checkmark$ & $\begin{array}{l}\text { Mild to moderate: psychological } \\
\text { treatment } \\
\text { Severe: SSRIs (either sertraline } \\
50 \mathrm{mg} \text { or citalopram } 20 \mathrm{mg} \text { ) +/- } \\
\text { psychological treatment } \\
\text { If individual fails two } \\
\text { antidepressant refer to psychiatry } \\
\text { If suicidal ideation or psychotic } \\
\text { symptoms urgent referral to } \\
\text { psychiatry }\end{array}$ & $\begin{array}{ll}\checkmark & \text { Consider interaction with inducers } \\
\checkmark & \text { Consider side effects of SSRIs (i.e. } \\
\text { hyponatraemia, sexual dysfunction, } \\
\text { osteoporosis, bleeding, weight gain) }\end{array}$ \\
\hline Anxiety disorders & $\checkmark$ & $\begin{array}{l}\text { Mild to moderate: psychological } \\
\text { treatment } \\
\text { Severe: SSRIs (either sertraline } \\
50 \mathrm{mg} \text { or citalopram } 20 \mathrm{mg} \text { ) +/- } \\
\text { psychological treatment } \\
\text { If fails two interventions refer to } \\
\text { psychiatry }\end{array}$ & $\begin{array}{l}\checkmark \quad \text { Consider interaction with inducers } \\
\checkmark \quad \text { Consider side effects of SSRIs (i.e. } \\
\text { hyponatraemia, sexual dysfunction, } \\
\text { osteoporosis, bleeding, weight gain) }\end{array}$ \\
\hline
\end{tabular}




\begin{tabular}{|c|c|c|}
\hline $\begin{array}{l}\text { First episode } \\
\text { psychoses }\end{array}$ & $\begin{array}{ll}\checkmark & \text { Urgent referral to psychiatry } \\
\checkmark & \text { First choice: Risperidone } \\
\checkmark & \text { Second choice: Olanzapine or } \\
& \text { quetiapine }\end{array}$ & $\begin{array}{l}\checkmark \text { Consider interaction between quetiapine } \\
\text { and inducers (.ie. undetectable levels of } \\
\text { quetiapine up to } 700 \mathrm{mg} \text { when in } \\
\text { combination with carbamazepine) } \\
\checkmark \quad \text { Consider side effects of antipsychotics } \\
\text { (.ie. sedation, weight gain with } \\
\text { olanzapine) }\end{array}$ \\
\hline $\begin{array}{l}\text { Attention deficit } \\
\text { hyperactivity } \\
\text { disorder }\end{array}$ & $\begin{array}{ll}\checkmark & \text { Methylphenidate } \\
\checkmark & \text { Psychological interventions }\end{array}$ & $\begin{array}{l}\checkmark \text { Review at transition to discuss } \\
\text { opportunity of continuing treatment } \\
\text { during adulthood }\end{array}$ \\
\hline $\begin{array}{l}\text { Psychogenic Non- } \\
\text { Epileptic Seizures } \\
\text { (PNES) }\end{array}$ & $\begin{array}{ll}\checkmark & \text { Explain diagnosis } \\
\checkmark & \text { Educate patients and caregivers } \\
& \text { about differences between PNES } \\
& \text { and epileptic seizures } \\
\checkmark & \text { Psychoeducational and } \\
& \text { psychotherapeutic interventions } \\
& \text { as in people with PNES only } \\
\checkmark & \text { Always refer to psychiatry to } \\
\text { identify other psychiatric } \\
\text { disorders in comorbidity } \\
\checkmark \quad \text { To treat other psychiatric } \\
\text { comorbidities (e.g. depression, } \\
\text { anxiety etc.) }\end{array}$ & $\begin{array}{l}\checkmark \quad \text { Individualised multidisciplinary approach } \\
\text { is always recommended }\end{array}$ \\
\hline
\end{tabular}

